\title{
Development and implementation of social work practice learning opportunities in NHS settings with no previous experience of social work education
}

\section{Marianne Hughes ${ }^{1}$}

Summary: The purpose of this paper is to outline the knowledge and practice used at a strategic, organisational and practice level in the planning and implementation of effective social work practice learning opportunities in NHS settings new to direct social work practice and social work education.

The paper outlines the process which was used in order to create new interprofessional practice learning opportunities and it is intended to add to 'process knowledge' (Sheppard et al., 2000). Additionally the paper draws on the content of the 'matrix of drivers and barriers to integrated working' developed for the area of interprofessional practice (Stewart, Petch, \& Curtice, 2003) and transfers this knowledge as applicable to Social Work education.

In practice, across human services, there continues to be views of 'other' professional groups that can create obstacles to the development and maintenance of positive inter-professional working, and that can undermine effective service delivery for service users (Report of Caleb Ness Inquiry, 2003). The experience of inter-professional practice learning, when combined with emotional intelligence (Morrison, 2007) can impact positively to increase the confidence, knowledge-base and direct inter-professional practice of newly qualifying Social Workers.

Keywords: inter-professional practice education; development of practice learning; emotional intelligence; strategic, organisational \& practice levels; development of professional identify

1. Social Work Education Consultant

Address for Correspondence: 2 Durham Road, Edinburgh, EH15 1NX. marianne@learningforpractice.co.uk

Date of publication: 30th November 2009

20 J. of Practice Teaching \& Learning 9(1) 2009, pp.20-45. DOI: 10.1921/146066909X481448. @ wEbb 


\section{Introduction}

Student: I wanted to learn, not just pass my placement.

Agency Manager: We wanted to achieve excellence in inter-professional learning

and issues that arose were not insurmountable.

Practice Learning Resources Manager: We were enthusiastic about the new journey we were on together, and discussed differences as they arose.

During the period 2005-2008 an initiative to promote inter-professional practice learning opportunities for social work students was undertaken in the Edinburgh \& Lothian areas of Scotland. The drivers for this initiative were the inter-professional requirements within the new Social Work Degree (Scottish Executive, 2003a); Scottish Executive policy which required an increase in the 'quality, quantity and diversity' of practice learning opportunities (Scottish Executive, 2003b) and ideas drawn from the Report of the 21st Century Social Work Review, Changing Lives (Scottish Executive 2006) relating to the development of autonomous Social Workers.

The terms inter-professional, multi-agency, and collaborative or integrated working are ones around which there are varying interpretations. Morris (2008, p.2) outlines the following interpretations:

- Multi-agency working as a process of arriving at some shared strategic goals but with single agency activity within the overarching plans;

- Multi-agency working as a process involving collective goals for service provision but with independent execution of the various tasks and activities by each professional at the point of service delivery;

- Multi-agency working as a shared process of both planning and direct delivery of services with co-location of staff and services.

She draws on work by Edwards et al. (2006), Littlechild (2008), and Coad (2008) to note that 'the boundaried nature of professional identities and agency cultures is repeatedly cited in the contributions as a barrier to the intended integrated arrangements' (p.3).

It was planned that by focusing on professionals in training some of the difficulties in working together could be circumvented and that newly qualified social workers could work in a more informed and constructive way with NHS colleagues in future, and vice versa.

The starting point for the initiative was a practice teaching unit within a council for voluntary service (Edinburgh Voluntary Organisations Council)

21 J. of Practice Teaching \& Learning 9(1) 2009, pp.20-45. DOI: 10.1921/146066909X481448. @ wEbb 
which had 20 years experience of developing working relationships with a variety of organisations for the purposes of securing diverse and high quality practice learning opportunities. A key part of the experience within this practice teaching unit was how to assist social work students to develop their professional identity as social workers within settings that were not traditional practice teams - that is settings where students were not surrounded by professionals named as 'social worker'.

The initiative focused on developing new social work practice learning opportunities (PLOs) in NHS settings that had no current direct social work involvement and no previous experience of social work education. There was a long period of negotiation leading up to the PLOs starting. The NHS agencies who offered PLOs cited their motivations as expanding the services received by service users, expanding their own knowledge of what social work could provide and learning more about child protection practice (particularly the NHS Substance Misuse Services). The model of multi-agency working adopted within the initiative fitted most closely to the second one (outlined above) by Morris (2008). Some of drivers that were present were:- realistic timescales; sense of momentum - 'the time is now'; open, honest, and transparent communication (Stewart et al., 2003).

It could be argued that a weakness in this paper is that it does not address how to dismantle barriers, resistance and obstacles in the endeavour to increase 'diversity' in PLOs. Although it took considerable time and persistence to identify the NHS agencies that came forward it was evident that, those that did come forward, were led by managers who demonstrated open-mindedness, positive interest and primal leadership skills (Goleman et al., 2002)

This paper explores why and how non-traditional settings can provide valuable practice learning in ways that strengthens students' development of their social work professional identity, and it reflects on the factors important in the implementation of this type of practice learning opportunity.

After an initial practice learning opportunity within a substance misuse service (specifically with a focus on drug use), a further three PLOs were undertaken in NHS settings with no prior involvement with social work or social work education - these spanned intensive anorexia nervosa services, alcohol problem services and drug services. 


\section{Knowledge underpinning the development and implementation of inter-professional practice learning opportunities}

Many practice teachers and educators will be familiar with a common concern voiced by social work students allocated practice learning opportunities outwith social work practice teams - 'how can I learn about social work here?'. For practice teachers, educators and students, it is a concern that requires an immediate, robust and reassuring response based on sound knowledge of social work theory, skills, values/ principles and current social policy. It requires, also, considerable negotiation with the settings in order to identify the potential for social work practice while as the same time valuing the service currently provided (in this case by the NHS). For this initiative there were four broad areas of knowledge that underpinned the development and the implementation.

Firstly, the psychological, sociological and social policy knowledge that social work draws on as a profession to understand human society, human difficulties and problems faced, and how this knowledge influences the interventions made by social work (towards internal and external change) in a way that differs from other professions (specifically, for this paper, health professionals). These areas of knowledge were important in informing the strategic question of 'why place social work students in health settings?' (or any non-social work setting where people with personal, social or environmental difficulties might seek assistance). These areas of knowledge (including systems theory; attachment and loss; stigma, discrimination and oppression; social model of mental health; transition and change; stages of human development; and organisational analysis) underpinned the teaching of the students in order to assist the development of their social work professional identities. In order for the students to develop confidence that they had an important service to offer they needed to have conscious awareness of, and be able to articulate the areas of knowledge that informed their assessments. Also, the managers within the health settings needed to have confidence in the knowledge that the students (and practice teacher) were drawing on for their practice. While there was some overlap in the knowledge used by both professions there were key differences in content and emphasis - which are explored later in this paper. Additionally, from a strategic point of view, the students

23 J. of Practice Teaching \& Learning 9(1) 2009, pp. 20-45. DOI: 10.1921/146066909X481448. @ wEbb 
needed to use the authority of their knowledge of social policy in order to understand that their location within non-traditional social work settings was part of a larger picture, for example, the Joint Futures and Partnership for Care agendas (Scottish Executive, 2000; 2003). They had to understand, also, some of the history behind the development of these policies. There is, unfortunately, knowledge from tragedies of the errors resulting from a lack of clear multi-agency and inter-professional working. For example, 'because the individual agencies were not working together effectively, the information was collated in a piecemeal fashion, and no single person knew all the relevant facts' and 'there was a tendency among professional in all agencies to make assumptions about the knowledge, training and actions of others' (Report of the Caleb Ness Inquiry 2003). The resulting policy initiatives, for example, Getting it Right for Every Child: Proposals for Action (Scottish Executive 2005), provided an impetus of service development in integrated working and policy initiatives in education, the impetus for new inter-professional training (NMC, 2007).

Knowledge of social policy informed both the development of the initiative itself and the content of learning for the students.

Secondly, an important area of knowledge that informed and influenced the initiative related to social work values and principles. This area of knowledge informed both the approach to the NHS professionals (in terms of respect for their profession - BASW Code of Ethics) and the practice in which the students' engaged with service users (SSSC Codes of Practice). These values extended to a consideration of 'location'. The question of how the physical location of a service can be experienced by service users due to how the location is viewed within society generally is an important one both in relation to enabling access and in terms of how the service user can feel when entering a building.

The idea of valued and devalued places drew on the work of Wolf Wolfensberger (1978).

While students may learn about stigma, discrimination, and oppression as experienced by individuals or families, it was useful to extend their learning into a consideration of how some physical locations and communities can be viewed and experienced as more or less stigmatised than others. For example, an appointment at the 'hospital' might be experienced by a service user in a way that an appointment at the 'social work department' might not - due to the stigma attaching to the associations with 'social work department'

24 J. of Practice Teaching \& Learning 9(1) 2009, pp.20-45. DOI: 10.1921/146066909X481448. @ w\&bb 
(or 'the welfare' as it is referred to within many communities). Also, however, the students needed to consider how the status of working within a health setting could enhance their power in the eyes of service users, and that this could operate oppressively. For all the social work students in health settings consideration was given to how to bridge this power differential in order to use a productive mode of co-operative power rather than a limiting mode of oppressive power (Tew, 2006), and to engage with people in understanding their human experience and lives as a whole (Doel \& Best, 2008). Additionally, knowledge of the emancipatory, therapeutic helping, and maintenance approaches - outlined by Dominelli (Adam et al., 2002) - were used to analyse the contested nature of social work practice through considering the differing values underpinning each of these approaches. This assisted students to 'ground' their own practice within the emancipatory and therapeutic helping approaches and this assisted in the development of their professional identities.

Thirdly, the initiative drew on knowledge of organisations (Handy, 1990), development of partnerships and change processes. As the background of the practice teacher was both social work and community development she was able to use knowledge of community development processes and apply these to the processes required to take the initiative forward. Within community development the gaining of, and maintenance of trust; an awareness of exercising power in different contexts; and a sensitivity to the use of language all featured as important aspects of the process (Rees, 1991).

Fourthly, the initiative drew on knowledge of adult education specifically Kolb's Learning Cycle (1984) - in order to develop practice learning experiences that ensured engagement with all four stages of the learning cycle, and that the NHS settings could provide learning to meet all aspects of the learning cycle (as this differed from some requirements within, for example, nursing training). It was necessary that the students were allocated and took responsibility for a workload. Their learning was more than observational and required concrete practice which could be reflected upon, critically analysed using theory and that conclusions could be drawn in order to plan next steps.

In Figure 1. (below), the importance of coherence between three inter-related aspects - strategic, organisational, and practice levels - is illustrated by the triangle surrounding the common purpose of the development of inter-professional practice learning. 
The knowledge that informed the strategic level was largely drawn from policy drivers relating to integrated working across services in both the NHS and social work, and from policy drivers within social work education (Confidence in Practice Learning) . It addressed the 'why?' questions:

- Why place social work students in NHS settings?

- Why accept social work students in NHS settings?

The first question was answered with reference to the holistic nature of human experience (drawing on psychological, sociological and social policy knowledge) and how social work intervention could add value to service users through interventions not used within the NHS (for example, differing approaches to group work; advocacy services in relation to housing, benefit, employment, community care; therapeutic work relating to loss; and strength-based approaches). It was also answered in relation to concerns highlighted in research around the lack of social work education in relation to responding to people with alcohol and drug problems (Morris, 2008). The second question was answered by a combination of NHS policy drivers, recognition of potential added value to service users, and increasing attention to child protection practice from within their own profession (NMC 2007).

The organisational level drew heavily on the third area of knowledge identified above (organisations, development of partnerships and change processes) and it also required knowledge of the key players with influence (Cialdini, 2001) within the NHS systems, plus knowledge of their likely interest and commitment to the idea of developing a new initiative. Clearly the knowledge from the strategic level (social and education policy drivers) was crucial for using at the organisational level in order to demonstrate how the initiative could take forward aspects of governmental thinking. A Clinical Development Manager in the NHS (identified through existing networks - outlined below) was contacted. He had influence within the NHS structures, interest in promoting inter-professional working and previously demonstrated commitment. Through discussion and the sharing of ideas around possible settings he committed to the identification of key operational managers within NHS service delivery. However, time and sensitive reminders about the initiative were required before the names of key operational managers were provided. Once this occurred the initiative was able to move to the practice level of implementation.

26 J. of Practice Teaching \& Learning 9(1) 2009, pp.20-45. DOI: 10.1921/146066909X481448. @ wEbb 
Within the practice level of implementation a number of 'what?' questions required to be addressed. Some of these questions were:

- What commonality factors could be worked with to establish a partnership between a NHS manager and the practice teacher?

- What areas of differences could be identified at the start and resolutions sought?

- What workload could a social work student undertake and what specific knowledge, skills and values learning could be gained?,

- What work was required to ensure clear roles were established for the key members of the training team?,

- What explanations would service users receive in relation to the service to be provided by the social work student?

The knowledge used for this level drew on all four areas outlined above.

Figure 1.

Development of inter-professional practice learning

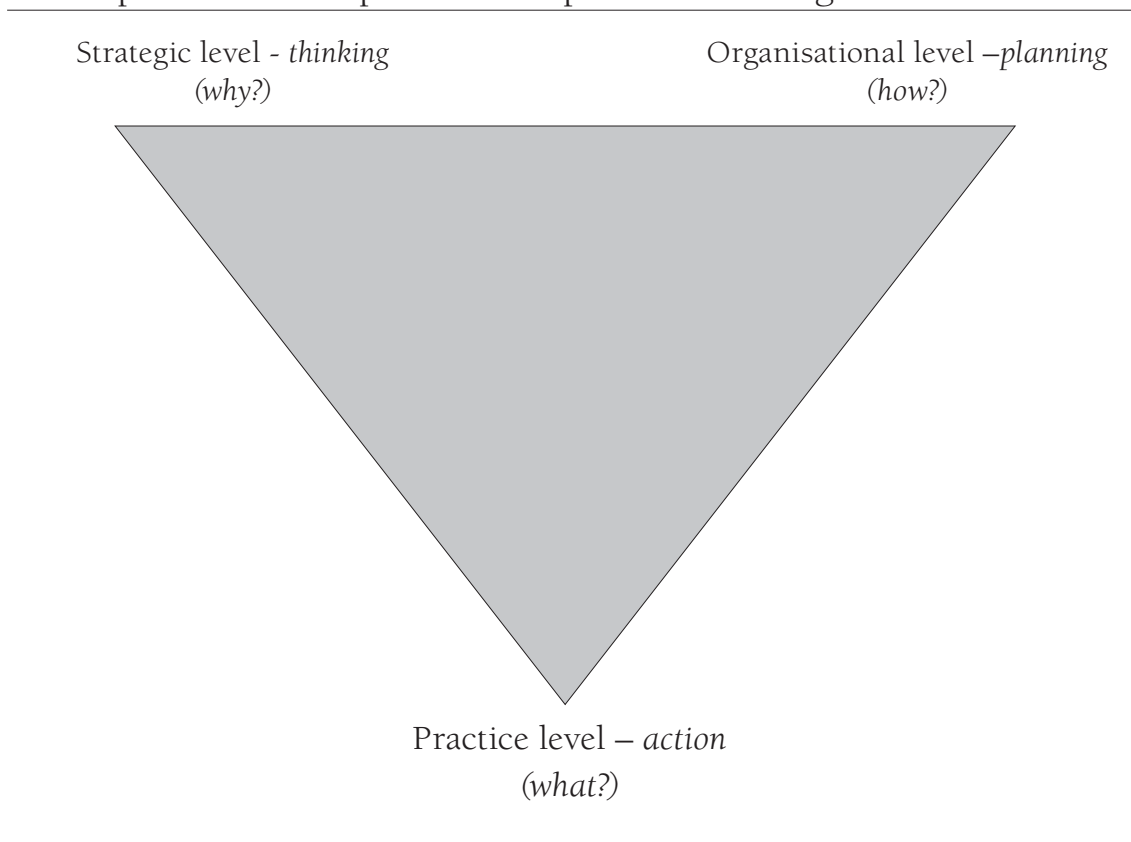

27 J. of Practice Teaching \& Learning 9(1) 2009, pp.20-45. DOI: 10.1921/146066909X481448. @ wEbb 
At the practice level the initiative required a variety of elements of partnership working. As the term 'partnership' has been used increasingly about inter-professional practice, it is worth considering what form it took in this context. In order to do this a model depicting five different levels of 'partnership' was drawn on as these levels represented increasing complexity and involvement between any organisations working closely together (Liddle \& Gelsthorpe, 1994). This model was developed to refer to service delivery, however the model has some uses in application to the development of practice learning opportunities where one organisation is supplying the PLOs and another organisation is providing the practice teaching or education and formal assessment of the student.

It was not necessary for the NHS agencies and the CVS to move towards 'merger' (5th level) or 'federation' (4th level) of organisations in order to develop the new initiative, but it was necessary to establish a 'communicating partnership' (1st level) which operated at the strategic level of developing the ideas and rationale - this type of partnership is based on the recognition by the agencies that they have a role to play in relation to each other. This was followed by a 'co-operating partnership' (2nd level) at the organisational level - this type of partnership is based on a agreement by both agencies to work on a mutually defined issue (in this case the education of social work students) but to maintain their separate boundaries and identities. A 'co-ordinating partnership' (3rd level) - where the agencies work together in a systematic way and may pool resources to tackle mutually agreed problems - was present, to some degree, at the practice level in terms of the way in which regular meetings and discussions took place throughout the placements themselves to ensure consistency of messages to the students, to reach agreements about work to be undertaken by the students, to resolve difficulties as they arose (for example around lone working) and to share feedback on students' progress.

Although the type of co-operation between the NHS agencies and the CVS can be understood using the above model this does not describe how the staff from the agencies behaved towards each other. For this to be understood it was useful to draw on the six generic partnership principles (Hudson \& Hardy, 2002) outlined for areas of social work service delivery, and to transfer these to the development and implementation of social work PLOs. These generic partnership principles: acknowledgement of need for partnership; clarity and 
realism of purpose; commitment and ownership; development and maintenance of trust; establishment of clear and robust partnership arrangements; and monitoring, review and organisational learning, were essential aspects of the development and implementation of the initiative. The importance of these factors is analysed below.

\section{Practice: The implementation of the inter-professional practice learning initiative}

\section{Description of starting points: Strategic level and practice levels}

During the 15 year history of the PQ Practice Teaching Award (to train practice teachers to work with social work students), a number of voluntary sector link supervisors (who were not SW qualified) undertook the PT Award and subsequently qualified. One individual who was nurse trained subsequently moved from a voluntary sector agency working with homeless people, into the NHS (Primary Care) offering a mental health intensive support service located in a GP practice. She was keen to continue to offer placements to social work students and her manager (NHS Clinical Development Manager) supported this initiative - the practice of the service fitted well with social work practice. She continued to be invited to, and attended, the CVS's Partnership Practice Teaching Group (which offers support to 'singleton' practice teachers across 40 voluntary sector agencies).

The CVS's Practice Learning Resources Manager (to act as the practice teacher for all the students) approached the NHS Clinical Development Manager who had supported the social work placements within the GP practice in order to develop the initiative. At this initial meeting it was established that NHS tertiary services with a mental health dimension would be a positive area within which to start. The development process was not without difficulties. There were a number of false starts, for example a manager who appeared supportive during face-to-face meetings but ended them with a list of difficulties. Clearly the context of change within the NHS made this additional initiative one that was difficult to prioritise. There was a period of several months of occasional meetings and exchanges of emails that culminated in a short paper

29 J. of Practice Teaching \& Learning 9(1) 2009, pp.20-45. DOI: 10.1921/146066909X481448. @ wËb 
initiated by the practice teacher outlining a planned pilot scheme. At this stage, knowledge from working within community development around persistence, recognition of the time needed for change processes, and the importance of maintaining direct contact with key players was all important to draw upon.

The paper, which the NHS Clinical Development Manager circulated to NHS managers, 'Practice Learning Requirements for the Social Work Degree' covered the organisation of practice learning, the role of the 'training team', the role of the link supervisor (and how this related to the more familiar 'mentor' role in the NHS) and the learning objectives for the student and included a direct request for a pilot scheme.

Managers within a substance misuse service and an anorexia nervosa service responded positively to the request for staff interested in taking part in a 'pilot scheme'. Their details were forwarded to CVS PTU, and initial meetings took place. These were followed up and the managers forwarded the CVS a range of policy documents relating to their areas of practice

\section{Key aspects of the strategic level}

There were a number of necessary conditions at a strategic level which contributed significantly to the progress of the initiative:

- policy initiatives within the NHS and social work education encouraging inter-professional learning;

- a senior manager committed to the ethos of inter-professional learning for students, and prepared to take action to raise the issue with other managers;

- committed, innovation-orientated managers within the agencies with direct experience of students and working within teams with experience of an inter-professional approach; and, additionally, who were interested, energetic, curious, with a strong commitment to staff training and prepared to take part in a new initiative without a clear sense of what the outcomes might be;

- a long-term funded social work education post which included a remit for development, innovation and delivery of practice learning opportunities, particularly in agencies undertaking social work practice without a specific post of 'social worker'.

30 J. of Practice Teaching \& Learning 9(1) 2009, pp.20-45. DOI: 10.1921/146066909X481448. @ wEb 


\section{Moving from strategic level to organisational level}

The CVS practice Teacher set up meetings with the senior managers in each of the interested agencies for the purpose of exploring the component parts that form the foundation of good quality practice learning, and to discuss the differences and similarities between social work and nursing/allied health professional practice learning education. These initial meetings generally took around two hours and covered:

- exploration of the make up of the staff group (remits, interests and background training), the specific service user group, the referral routes $\&$ allocation systems, the recording systems, the workload of each staff member, and the wider agencies/systems with which the teams interacted;

- exploration of the value base and theories used by staff in order to establish the common areas, and any areas of difference (plus provision of the SSSC Codes of Practice by the Practice Teacher);

- exploration of the methods of intervention used by the agencies and how social work methods of intervention could add to service provision;

- explanation about the Practice Teaching Unit and the responsibilities of the Practice Teacher;

- exploration of the expectations of the link supervisor role, and how similar and different this was from the mentor role within NHS education;

- provision and explanation of the Framework of Standards for Social Work Education in Scotland;

- exploration of the flexibility within the agency for students with specific needs, for example caring responsibilities;

- discussion about the content of student induction, including the agencies' health and safety procedures;

- discussion about the resources available to a student (desk, phone, computer);

- discussion about the enhanced disclosure status of the student (criminal record check);

- discussion about the range of assessment methods to be used during the practice learning, including direct observation of practice by the Practice Teacher and feedback from service users and colleagues;

- establishing the time commitment for the agencies in terms of

31 J. of Practice Teaching \& Learning 9(1) 2009, pp.20-45. DOI: 10.1921/146066909X481448. @ wEbb 
meetings with the Practice Teacher, and frequency of meetings with the student's university tutor;

- establishing dates of the practice learning and discussion of any holidays falling in this period and the 'cover' arrangements;

- an agreement from the managers to discuss the details of our discussion with her team;

- discussion about the next steps in terms of information about a specific student and a pre-placement meeting.

In terms of the six generic partnership principles (Hudson \& Hardy 2002) this aspect of the initiative related to 'development of trust', 'establishment of clear and robust partnership arrangements' and the building 'clarity and realism of purpose'.

Another aspect of the initial meetings was the exchange of personal and professional information between the managers and the Practice Teacher as the first stage of forming a working relationship that required openness and clarity so that the student did not become confused by encountering differing expectations. This aspect of the relationship building drew on intrapersonal and inter-personal aspects of emotional intelligence, self-awareness from both the Practice Teacher and NHS managers plus relationship management skills between each other (Morrison, 2007). For example, it included expression of uncertainty about how the students' work might develop as well as commitment to ensure a good level of communication throughout the actual placements.

\section{Key aspects of the organisational level}

The initial meetings established that there were positive and key aspects of interest or commonality between the NHS approaches and the required learning for social work students:

- the NHS approaches to service users was underpinned by values which bore similarities to social work values, however language differences (for example 'patient or client' and 'service user') often signified differences that (later on) became significant;

- though the theory base used by NHS staff contained a number of 'cross-over' areas with social work (for example motivational interviewing, a social model of mental health, models of vulnerability

32 J. of Practice Teaching \& Learning 9(1) 2009, pp.20-45. DOI: 10.1921/146066909X481448. @ wEb 
and resilience), significant differences arose later with social work students drawing more on strength-based models plus knowledge of stigma, discrimination and oppression;

- an openness to the 'added value' that a social work student could bring to the service and an interest in hearing about the social work perspective on, and practice in specific areas of work, for example child protection;

- a current and active approach to inter-professional working by the NHS teams;

- an active involvement and support from senior consultants who managed the NHS teams;

- a commitment from the managers to use team meetings in order to encourage, to include staff in the initiative and to seek their agreement before starting, and where possible an invitation to the Practice Teacher to a team meeting;

- a clear organisational base and accountability systems for the Practice Teacher;

- a clear outline, through example, of a 'working agreement' of the boundaries, roles and expectations within the practice learning opportunity.

\section{Moving from the organisational level to the initial stages of the practice level: Implementing the placements}

Several aspects of the implementation had to be taken into account in order to facilitate as positive an experience of the initiative as possible:

- the matching of suitable students to the practice learning opportunities, and in particular the interests and attitude of the students ascertained from the university profile forms completed by the students themselves;

- the specific support needs of the student (for example one student had a diagnosis of dyslexia; another student had caring responsibilities);

- the practical arrangements for the start, the student meeting the agency staff and the induction programmes;

33 J. of Practice Teaching \& Learning 9(1) 2009, pp.20-45. DOI: 10.1921/146066909X481448. @ wËb 
- the student meeting with the Practice Teacher and discussion of the Practice Teacher's role in 'holding' the social work aspects of the practice learning opportunity (as noted above, a key area of student anxiety when placed in settings with no named social worker).

The 20 years of experience of the CVS PTU in arranging and in delivering practice learning opportunities meant that there was a good understanding of the 'duty of care' to the agencies and to the students. As there had never been a requirement for voluntary sector agencies to offer social work practice learning it was important to maintain relationships in order that interest and good will was cultivated and preserved. This 'duty of care' work transferred well into the NHS agencies as there was, again, no requirement to offer social work practice learning.

The first step of implementation was a discussion with the universities in order to identify students who would be interested and enthusiastic about this practice learning opportunity. The Practice Teacher's analysis of the PLOs on offer led her to decide that the students would need to be in their final placement and preferably be students with a range of previous work experience who would not be intimidated by the potential complexity of working in a social work role within a predominantly medical setting. This was discussed with the various university placement coordinators.

\section{Key aspects of the initial stages at the Practice Level}

- the existence of a good relationship between CVS PTU and the Scottish universities so that an open discussion could take place with the universities practice learning co-ordinators;

- the matching of students who fulfilled specific criteria in order to make full use of the practice learning opportunities being offered;

- an exploration with the students concerning specific needs and concerns so that these were established before the start date, and reasonable adjustments could be made;

- early pre-placement meetings were arranged so that any adjustment could be implemented beforehand (this was two or three weeks before the start date);

- a clear induction programme for the students' first two weeks was created by the NHS managers, as this provided the students with a

34 J. of Practice Teaching \& Learning 9(1) 2009, pp.20-45. DOI: 10.1921/146066909X481448. @ wEbb 
focus and a sense of being included from the first day of placement;

- open discussion about the social work role and how the practice learning opportunity could assist the student to meet the required standards in social work education.

\section{Analysis of the initiative: Practice Level}

While this analysis is based on the experience of only four students across different NHS settings, there were commonalities across all the situations in relation to the areas of learning from which the students benefited and in relation to the areas of student work that were valued by the NHS teams and the service users.

All the students commented favourably on their increased knowledge in relation to NHS systems, staff roles, medical information and service provision. Also, they all expressed an increase in confidence in approaching NHS colleagues in general.

These outcomes were useful ones - in particular the increase in confidence, as this has been shown to be one of the requirements for future effective multi-agency working (Galvani 2008). In terms of expert knowledge they expressed increased confidence in being able to talk about the area of practice (mental health in general and in particular substance misuse or anorexia nervosa), the approaches used by NHS staff and the valuable contribution social work could make to service provision in NHS settings. Additionally, all the students stated that they had found access to social work orientated supervision vital and that they would see this as an essential aspect of practice for social work practitioners within multi-professional teams.

While all the students had considerable and varied prior experience, they all had to engage with a steep learning curve in relation to the purpose, ethos, practice and procedures within the NHS settings. As one student noted 'facing the question - what do social workers do? - on my first day was daunting'.

The following factors appeared to influence positive progress of the practice learning experience:

- The degree of emotional intelligence of students

- The processes use to integrate students into the NHS setting

- The early development of a varied workload

35 J. of Practice Teaching \& Learning 9(1) 2009, pp.20-45. DOI: 10.1921/146066909X481448. @ wEbb 
- The content of weekly supervision with the Practice Teacher

- The regularity and content of meetings between student, manager/ link supervisor and Practice Teacher

\section{Emotional intelligence}

An interest in mental health and in the NHS as a setting, (new to all the students) were common factors between the four students. In terms of personal qualities the three students who demonstrated the greatest resilience and maturity both rated the experience most positively and were rated most positively by NHS staff. The least positive experience (of the second student in the drugs service) appeared to relate to her having less ability to contain her anxieties when relating to immediate NHS colleagues, which resulted in her being experienced less positively than other students. The other students too had high levels of anxiety, but used weekly supervision and their daily reflective journals to express and manage their feelings. This resulted in less 'spill over' into their daily practice so that their anxiety was less evident to NHS colleagues. The capacities of awareness of own anxiety, use of appropriate methods to express feelings and the resulting managing of agency relationships in a constructive way were all evidence of high emotional intelligence on the part of these three students. This factor appeared to be key in the progress made by them and in how positively they were rated by service users and colleagues. It is not possible to conclude whether this factor alone could have been selected for in the matching of the students to the PLOs, however these experiences suggest that an assessment of emotional intelligence in social work students prior to practice learning could be a useful and important assessment tool. It suggests, further, that emotional intelligence could be a useful focus for overt learning within social work Education in order to develop this capacity during the social work degree.

\section{Integration of students into NHS settings}

Regardless of the levels of confidence the majority of students start practice learning with a concern about how the staff in the agency will act towards them. In the NHS settings this concern was increased as

36 J. of Practice Teaching \& Learning 9(1) 2009, pp.20-45. DOI: 10.1921/146066909X481448. @ wEbb 
the students did not know how they would be received as social work, rather than health, students. The positive feedback from the students contained comments like 'the team was warm and welcoming - this helped me settle in'. In addition to these personal elements of the beginning - which indicated a high level of emotional intelligence on the part of the NHS staff - the structure and content of the induction programme was a crucial influence on how the students integrated and were assisted to build knowledge in a way which developed their confidence in practice. The most positive experiences were where the induction programme had been developed to involve the student in 'shadowing' experiences and one-to-one meetings with a variety of team members. These opportunities assisted in forging relationships that later enabled the students to feel personally and professionally confident in approaching the team members to discuss specific areas of work. Also, the learning gained from shadowing was critical in the development of practice skills, for example in the substance misuse services students had to learn a range of medical language and factual knowledge about substitute drugs, and they had to be able to adopt aspects of role (within clinic based work) with confidence and accuracy (for example learning how to take urine samples and oral mouth tests and assess the results - with supervision). within the anorexia nervosa service students benefited from time with the clinical psychologist, dietician and assistants psychologists in understanding the life-threatening physical impact of anorexia nervosa, their interventions in relation to mental and physical health and how they worked with GPs, nurses and families.

All the students commented favourably on NHS staff who expressed interest in their education, curiosity about the place social work could play alongside their own work, and who sought them out to discuss practice questions. This happened most frequently in relation to child protection issues that required the social work students to draw heavily on their own education at university and previous practice experience, and in relation to aspects of independent living, for example systems of housing, benefit, employment and on-going support provision.

\section{Development of workload}

The complexity of the individual, family and group work undertaken

37 J. of Practice Teaching \& Learning 9(1) 2009, pp.20-45. DOI: 10.1921/146066909X481448. @ wEbb 
by the NHS services lent itself very well to the work required of social work students on their final placements

The criteria for receiving a service from the substance misuse services related to dual diagnosis - substance misuse plus mental health issues, pregnancy, or physical health issues.

The nature of the anorexia nervosa services focused on individuals at risk of imminent hospital admission due to the life-threatening level of their body-mass index (BMI), and who had expressed a wish to avoid hospital admission through intensive support to stay at home. The work meant, therefore, that students were able to undertake complex holistic assessments using a range of theory and to work with a range of intervention methods - often interventions were multi-faceted with the same individual or family across the time of the placement. The approaches included working to maximise income through benefit checks and advocacy; working to further housing applications or re-housing; working to explore the impact of past events (including abuse issues) on current self-worth and identity and to increase selfconfidence; working to assess risk and protective factors in child care situations in addition to exploring the motivation to change drug-misuse behaviour; strength-based approaches to developing skills and abilities in times of good health; working in the 'life-space' taking time to undertake activities; developing 'social capital' through the development of networks to sustain change beyond SW involvement.

Overall the students were provided with complex work with individuals, families and - in some situations - group work. It was most useful where the NHS agency had identified a few individuals, families and a group as possible areas of work for a social work student prior to the starting date as this provided an opportunity for the students to gain a concrete sense of the practice realities.

\section{Content of weekly supervision sessions}

The weekly supervision sessions (each up to two hours in length) between the individual students and the Practice Teacher was crucial both for the learning in relation to the social work role and in terms of the students' abilities to learn in circumstances which were challenging for them despite their considerable previous experience (Lefevre, 2005).

The areas of knowledge that students drew on which differed from the

38 J. of Practice Teaching \& Learning 9(1) 2009, pp.20-45. DOI: 10.1921/146066909X481448. @ wEbb 
common areas of knowledge between themselves and NHS colleagues included theoretical knowledge in the areas of stigma, discrimination and oppression plus systems theory (in relation to communities and other service systems). Additionally, the methods of intervention which students used, following comprehensive assessments, differed from NHS methods, for example the use of advocacy methods (particularly in relation to social issues of housing, benefits, employment/training), group work with active peer-support dimensions and the use of strength-based therapeutic approaches influenced by transactional analysis. Each student completed a daily reflective journal that was sent to the Practice Teacher on a weekly basis and this formed an aspect of the supervision agenda. The format of the reflective journal encouraged an analysis of knowledge, skills and values being used in practice by themselves and by colleagues. Often the students identified approaches in practice with which they disagreed and they had to analyse their reasons - this process led into the development of their social work professional identity. For example, one student was keen to seek specific permission from a service user in relation to his psychiatric records (he had signed a general consent form in relation to access to files and this was taken as permission within the NHS team). In terms of equalising power as much as possible, the student sought to discuss this specifically with the service user (as it would assist his DLA application), taking an open approach to information that is emphasised in social work education. In another situation, the student had to work closely with one family where there were child protection issues. She sought to work in partnership - visiting the family to explain face-to-face her concerns and why she needed to refer their situation to the local authority team, and agreeing to visit the family with the letter/report she intended to send in order that they could state their views and have these included in the report. This type of 'working alongside' in the difficult area of child protection was different from the procedure usually used within the NHS setting - however it was accepted within the team as good practise. In another situation, the student questioned the use of the term 'girls' to refer to women in their twenties and analysed the impact of infantilising language on working in an adult to adult way.

The main differences that emerged related to values - either directly or in terms of the values underpinning the knowledge used to assess or intervene.

39 J. of Practice Teaching \& Learning 9(1) 2009, pp. 20-45. DOI: 10.1921/146066909X481448. @ w\&bb 


\section{Regular meetings of the training team}

Throughout the placement periods the students, managers, link supervisors and Practice Teacher met every three or four weeks as 'an acknowledgement of the need for partnership' in order to achieve a quality practice learning opportunity for the student, and as part of 'ongoing monitoring and review'. These two aspects are part of the suggested six generic partnership principles (Hudson \& Hardy 2002). In the evaluation feedback the managers all stated that this frequency of meetings was useful due to the new experience, and they thought that they learned about the types of interventions that could benefit service users through the detailed workload discussions that took place.

One of the key principles for effective inter-professional working - transferred to inter-professional learning for students - was the 'management of conflicts through exploration of expectations' (Carnwell $\&$ Buchanan 2005). The areas of difference in practice that arose were discussed openly between the students, the managers and the Practice Teacher. This was of vital importance and the experience was one in which the students' learning was placed centrally and discussed in a way which demonstrated a flexible approach by each of the NHS teams. For example, in order for students to undertake holistic assessments and intervention work they were required to visit people in their own homes (unless the risks were too high). Due to pressure of work this was difficult for NHS staff (in substance misuse services) to undertake but there was full support for this aspect of students' learning.

\section{Additional value to the NHS teams}

It was clear to the Practice Teacher and to the students that the NHS teams placed a strong emphasis on research findings in relation to practice and on staff training - and students were included, valuably, in staff training during their placements. The emphasis on the application of research to practice was very welcome, as this is one the areas of growing attention in social work practice and this experience was, therefore, of positive value for the students.

It would, in hindsight, have been useful to have undertaken a more systematic and in-depth analysis of the impact, on each of the NHS teams, of the social work student's practice and ascertain the increase

40 J. of Practice Teaching \& Learning 9(1) 2009, pp.20-45. DOI: 10.1921/146066909X481448. @ wEbb 
in understanding about the social work profession. However, the NHS teams provided particularly positive feedback about the placements where the students had actively promoted an understanding of their practice to the wider team (this was encouraged by the Practice Teacher in supervision). These students were experienced as positive ambassadors for social work as a profession.

Three of the four students contributed significantly to the NHS teams understanding of the contribution that could be made by social work. One student made a presentation to the Drug Action Team, using examples of specific work she had undertaken which highlighted the work and the outcomes for service users of integrating social work expertise into the NHS services. Another student presented her work to the new consultant and whole team within the anorexia nervosa services - again using examples of direct practice, her assessments, her interventions and the outcomes for the service users. Another student whose workload included group work with people misusing alcohol developed the practice to be more active, inclusive, and valuing of the social capital of experienced members. She developed all the exercises into a booklet for future group leaders to use.

While it could be argued (accurately) that it is not the role of students to be ambassadors for their chosen profession, in these situations the strength of three of the four students was such that they developed a further passion for their social work practice within the NHS settings and they were keen to promote the beneficial impact their profession could make.

Three of the NHS settings did, subsequently, present a case for social work posts to their senior managers and two of these were successful (one in securing a part-time secondment).

\section{Concluding comments}

One of the students, the manager and the Practice Teacher presented a workshop at the PEPE 2008 International Conference. They developed a workshop in which the participants were asked to imagine themselves in the role of a prospective student, agency manager and practice teacher undertaking this new social work practice learning initiative within a NHS setting. The concerns and anxiety were marked in the workshop

41 J. of Practice Teaching \& Learning 9(1) 2009, pp. 20-45. DOI: 10.1921/146066909X481448. @ wËb 
participants' feedback, while the comments of the three actual people who had experienced the situation were far more optimistic.

It was instructive to be reminded of what Hudson (2002) refers to as the 'pessimistic tradition' in relation to inter-professional working, and to see how this could colour approaches to inter-professional practice learning if the selection of participants did not attend to some of the factors (outlined in this paper) which were necessary for a positive learning experience to be achieved. In preparing social work students for professional practice where the issues of substance misuse (in particular) occur in increasingly wide-spread aspects of life and mental health issues occur across all areas of social work practice, more attention to the inter-professional aspects of these within education and training would be beneficial (Galvani, 2008).

The existence of policy drivers within service provision and within tertiary education were necessary factors for this initiative at a strategic level, as was the existence of personnel at a strategic level willing and able to forward the policy agendas. These were not, however, sufficient to ensure action on the ground. This required energy, time, focused remit and commitment at the organisational and practice levels.

In turn, this required professionals who were in relatively secure posts (with at least three years of funding), who were interested, committed and able to conceive the long-term planning required in order to achieve the foundations necessary in the initial stages.

In conclusion, from the written evaluations undertaken by all parties at the end of all the CVS/NHS placements, this is a selection of comments from the social work students, as they were the 'service users' of these practice learning experiences:

I was treated in a professional manner with a clear structured induction programme.

Shadowing staff in the clinics was vital for me to understand their jobs.

The staff members were aware that I was a social work student and were friendly, caring and very accommodating. They were as interested in my training as I was learning from them. The space provided was excellent and the administrative support very helpful and accommodating.

I was trusted to provide a broad range of services - negotiating with housing, benefits, employment agencies - and this developed the team's view of what social work could contribute.

42 J. of Practice Teaching \& Learning 9(1) 2009, pp.20-45. DOI: 10.1921/146066909X481448. @ wEb 
Both my link supervisor and the G-grade nurse provided copies or information of the agency policies and procedures. Due to the nature of the placement and different working practice collaboration was important. The placement experience has made me more prepared to work in a diverse range of settings.

I was extremely grateful to be given this placement opportunity. It allowed me to build on my skills and knowledge from previous employment, Year 1 placement and academic learning. It gave me a real insight into substance misuse, collaborative practice and social work's role. The support I received from the agency staff, practice teacher, and my tutor I felt very privileged to have.

\section{References}

Adam, R., Dominelli, L., and Payne, M. (2002) Social Work: Themes, Issues And Critical Debates. (2nd ed) Buckingham: Open University

British Association of Social Work (2002) The Code of Ethics for Social Work. Birmingham: BASW

Carnwell, R. and Buchanan, J. (2005), Effective Practice in Health and Social Care: A partnership approach, Maidenhead: Open University

Cialdini, R. B. (2001), Influence: Science and practice,. Upper Saddle River, NJ: Allyn \& Bacon

Coad, J. (2008), Bringing together child health and social care provision: challenges and opportunities for multi-agency working. in K. Morris Social work and Multi-Agency Working: Making a difference. Bristol: Policy Press/BASW

Doel, M. and Best, L. (2008) Experiencing Social Work: Learning from service users. London: Sage

Edwards, A. et al (2006) Working to Prevent the Social Exclusion of Children and Young People: Final lessons from the National Evaluation of Children's Fund, RR 734, London: DfES

Galvani, S. (2008) Working together: Responding to people with alcohol and drug problems. in K. Morris Social work and Multi-Agency Working: Making a difference. Bristol: Policy Press/BASW

Goleman, D., Boyatzis, R., and McKee, A. (2002) The New Leaders: Transforming the art of leadership into the science of results. London: Sphere

Handy, C. (1990) Inside Organisations: 21 ideas for managers. London: BBC Books

43 J. of Practice Teaching \& Learning 9(1) 2009, pp.20-45. DOI: 10.1921/146066909X481448. @ w\&b 
Hudson, B. (2002) Interprofessionality in health and social care: The Achilles' heel of partnerships? Journal of Interprofessional Care, 16, 199-210

Hudson, B. and Hardy, B. (2002)What is 'successful' partnership and how can it be measured?. in C. Glendinning, M. Powell, and K. Rummery, K (Eds.) Partnerships, New Labour and the Governance of Welfare'. Bristol: Policy Press Kolb, D.A. (1984) Experiential Learning. Englewood Cliffs, NJ: Prentice Hall

Lefevre, M. (2005), Facilitating practice learning and assessment: The influence of relationship. Social Work Education, 24, 5, 565-583

Liddle, A.M. and Gelsthorpe, L. (1994) Crime Prevention and Inter-agency Co-operation. Police Research Group Crime Prevention Unit Series: Paper No. 53. London: Home Office Police Department

Littlechild, R. (2008), Social work practice with older people: Working in partnership, in K. Morris Social work and Multi-Agency Working: Making a difference. Briston: Policy Press/BASW

Morrison, T. (2007) Emotional intelligence, emotion and social work: Context, characteristics, complications and contribution. British Journal of Social Work, 37, 245-263

NMC (Nursing Midwifery Council) (2007) Interprofessional Working. www. nmc-uk.org.uk/interprof [accessed 30.6.09]

Rees, S., (1991), Achieving Power: Practice and Policy In Social Welfare. London: Allen and Unwin

Report of Caleb Ness Inquiry (2003) Report of Caleb Ness Inquiry Commissioned by Edinburgh \& Lothians Child Protection Committee. (www.edinburgh.gov. uk/internet/council/council_publications/cec_report_of_the_caleb_ness_ inquiry) [accessed 30.6.09]

Scottish Executive (2000) Community Care: A joint future, Edinburgh: Scottish Executive

Scottish Executive (2003) Partnership for Care: Scotland's Health White Paper, Edinburgh: Scottish Executive

Scottish Executive (2003a) The Framework for Social Work Education in Scotland, Edinburgh: Scottish Executive

Scottish Executive (2003b) Confidence in Practice Learning. Edinburgh: Scottish Executive

Scottish Executive (2005) Getting It Right for Every Child: Proposals for action. Edinburgh: Scottish Executive

Scottish Executive (2006) Report of the 21st Century Social Work Review: Changing lives, Edinburgh: Scottish Executive

Scottish Social Services Council (2003) SSSC Codes of Practice. Edinburgh: SSSC

44 J. of Practice Teaching \& Learning 9(1) 2009, pp.20-45. DOI: 10.1921/146066909X481448. @ wEbb 
Sheppard, M. Newstead, S., Di Caccavo, A., and Ryan, K. (2000) Reflexivity and the development of process knowledge in social work: A classification and empirical study. British Journal of Social Work, 30, 465-488

Stewart, A., Petch, A., and Curtice, L. (2003) Towards integrated working across health and social care in Scotland: From maze to matrix. Journal of Interprofessional Care, 17, 4, 335-50

Tew, J. (2006) Understanding power and powerlessness: Towards a framework for emancipatory practice in social work. Journal of Social Work, 6. 1.33-51

Wolfensberger, W. (1978) The ideal human service for a societally devalued group. Rehabilitation Literature, 39, 9, 15-17 